\title{
Chemo-Mechanical Evaluation of Asphalt Mixtures Reinforced With Synthetic Fibers
}

\author{
Moises Bueno* and Lily D. Poulikakos \\ Empa - Swiss Federal Laboratories for Materials Science and Technology, Duebendorf, Switzerland
}

\section{OPEN ACCESS}

Edited by:

Castorina Silva Vieira, University of Porto, Portugal

Reviewed by:

Xiaoming Huang,

Southeast University, China

Gholam Hossein Hamedi,

University of Guilan, Iran Decheng Feng,

Harbin Institute of Technology, China

*Correspondence:

Moises Bueno

moises.bueno@empa.ch

Specialty section:

This article was submitted to

Sustainable Design and Construction,

a section of the journal

Frontiers in Built Environment

Received: 10 December 2019

Accepted: 20 March 2020

Published: 09 April 2020

Citation:

Bueno M and Poulikakos LD (2020) Chemo-Mechanical Evaluation of Asphalt Mixtures Reinforced With

Synthetic Fibers.

Front. Built Environ. 6:41. doi: 10.3389/fbuil.2020.00041
The use of additives in asphalt mixtures has been an important option in order to prolong the durability of the road infrastructure. Several works have reported that the utilization of synthetic fibers (e.g., plastic fibers) visibly enhance the overall mechanical performance of asphalt mixtures. The objective of this experimental study is to understand the physicochemical mechanisms leading to this superior response. With this in mind, two synthetic fibers were selected in order to analyze their effect within a conventional dense asphalt mixture used in Switzerland. The mechanical performance of the experimental mixtures along with the thermal properties of the fibers were evaluated. First, it was concluded that the fiber reinforced asphalt mixtures could perform similarly to the standard mixtures prepared with polymer modified binder. In addition, it was confirmed by imaging analysis that the reinforcing effect was associated to the physical presence of the fibers within the asphalt matrix.

Keywords: synthetic fibers, asphalt mixtures, road, mechanical performance, reinforcement, aramid, polyacrylonitrile

\section{INTRODUCTION}

The increase of heavy traffic and the effect of the climate change are the main questions that new designs for asphalt roads must address in the near future. The overall objective of road transportation must include a reduction of the maintenance frequency of road works usually linked to economic costs involving construction and utilization of new materials as well as higher commuting times for the users. In order to build better road infrastructures with longer service life, new solutions must be investigated and adapted to improve their current mechanical performance by reinforcing the asphalt matrix (Laurance et al., 2014; European Asphalt Pavement Association [EAPA], 2017).

Recently, in order to increase their durability, different types of synthetic fibers have been used as additives to the asphalt mixtures for road construction (Slebi-Acevedo et al., 2019). In particular, different studies have reported the remarkable improved low temperature behavior of asphalt mixtures modified with polypropylene and polyester fibers [(Button and Hunter, 1984; Simpson and Mahboub, 1994). Likewise, aramid fibers in combination with polymeric fibers (i.e., polyolefins) have clearly shown promising results in regards to formation of cracks as well as permanent deformation (Kaloush et al., 2010; Ho et al., 2016; Aliha et al., 2017; Mirabdolazimi and Shafabakhsh, 2017; Klinsky et al., 2018; Noorvand et al., 2018; Souliman et al., 2019)]. Some researches describe that the incorporation of aramid fibers cause an enhancement of the reinforcing 
network within the asphalt matrix whereas the role of the polyolefins is more related to ease the dispersion of these fibers and improve the adhesion properties of the mixture. In addition to this, several investigations have confirmed the potential of polyacrylonitrile fibers as suitable additive for asphalt mixtures (Xu et al., 2010; Chen and Xu, 2010; Weise and Zeissler, 2016). It seems clear that the use of this type of fibers leads to a significant rutting resistance performance as well as achieving the required strength for an acceptable mechanical response of the material. Nevertheless, there is still a need to clarify and corroborate the different hypotheses associated to the enhancement of the mechanical response linked to the fibers addition.

The aim of the current research work is to experimentally evaluate the reinforcing effect of different synthetic fibers on the performance of a conventional dense asphalt mixture for base layers. This investigation is mainly focused on understanding the fundamental mechanisms governing the microstructural properties behind the overall behavior. The added functionality of the fiber reinforced materials is analyzed by using advanced characterization techniques. The mechanical performance of several asphalt mixtures is correlated to specific factors such as thermal properties of the fibers, their distribution within the asphalt matrix or the rheological response of the recovered binders after the fiber incorporation.

\section{MATERIALS AND METHODS}

In this study, two commercially available fibers, designated as Type A and Type P, were selected to investigate the effect of their incorporation into conventional dense asphalt mixtures. Type A supplied by FORTA ${ }^{\circledR}$ Corporation (United States) consists of a combination of aramid (A1) and polyolefins (A2) fibers of $38 \mathrm{~mm}$ and $18 \mathrm{~mm}$ lengths, respectively. The ratio of this blend defined by the supplier was approx. 1:7 (aramid:polyolefins). The other type is polyacrylonitrile fibers (type P) of $4 \mathrm{~mm}$ length and nominal diameter ca. $10 \mathrm{~mm}$ supplied by Lambda Furtherance B.V. (Netherlands). Images of both types of fibers are shown in Figure 1.

Four dense asphalt mixtures base course AC B $22 \mathrm{H}$ according to the Swiss standard SN 640-436 (VSS, 2013) were prepared and different specimens and slabs were compacted in order to evaluate their mechanical properties. Table 1 summarized the four different asphalt mixtures: one control mixture with

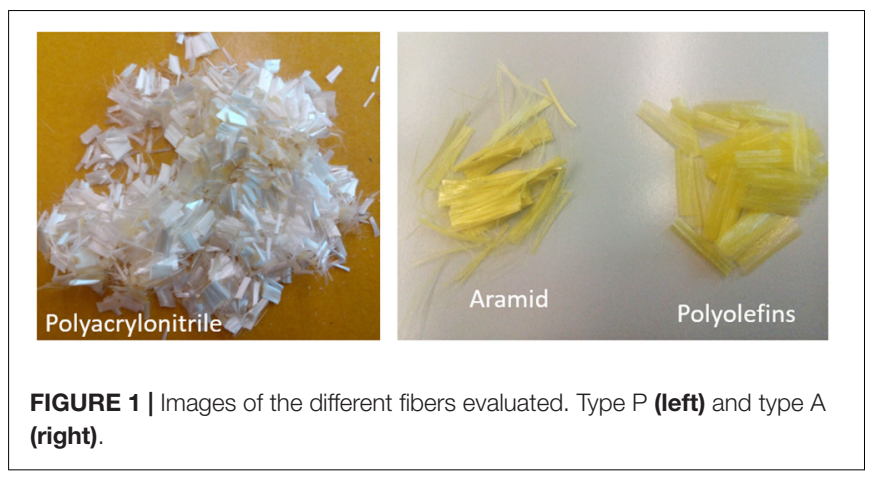

TABLE 1 | Dense asphalt mixtures (AC B $22 \mathrm{H}$ ) prepared for the experimental study.

\begin{tabular}{lcc}
\hline Name & Bitumen (4.2\%) & Fiber \\
\hline ACB22H - Control & PmB 45-80/65 & - \\
ACB22H - Reference & $50 / 70$ & - \\
ACB22H - Type P & $50 / 70$ & $\mathrm{P}(0.15 \%)$ \\
ACB22H - Type A & $50 / 70$ & $\mathrm{~A}(0.05 \%)$ \\
\hline
\end{tabular}

polymer modified bitumen $(\mathrm{PmB} 45-80 / 65)$ as required by the standard, one reference mixture with base bitumen 50/70 and two fiber reinforced asphalt mixtures (FRAMs). Fiber content was recommended by the manufacturers as follows: type A content $0.05 \%$ and type $\mathrm{P}$ content $0.15 \%$ by weight of the entire mixture.

Following guidelines provided by the fiber producers, the dry process was used to prepare the FRAMs as follows, fibers are added directly with the aggregate fraction and no previous modification of the bitumen is done. Although fibers are incorporated directly into the mixer in the asphalt plant, a special protocol for mixing at lab scale was recommended for fiber Type A in order to improve the fiber distribution within the mixtures. It was suggested that the aramid fibers (A1) were mixed first with the preheated mineral aggregates whereas the polyolefins fibers (A2) were added with the hot bitumen. First, the aramid fiber content was separated into two equal parts. Once the preheated $\left(160^{\circ} \mathrm{C}\right)$ coarse aggregate fraction was added to the mixer, one part of the aramid component was introduced. Afterward, half of the content of fine aggregates plus the remaining content of aramid component were added to the mixer followed by the rest of fines. Finally, the entire polyolefins component fiber was incorporated to the pre-heated bitumen $\left(4.2 \%\right.$ wt.) at $160^{\circ} \mathrm{C}$ to immediately be poured into the mixer for $2.5 \mathrm{~min}$ mixing. In the case of the Type $\mathrm{P}$ fiber, the entire fiber content was added to the preheated mineral aggregates before pouring the hot bitumen. For the reference and control asphalt mixtures which were prepared without fibers, the conventional mixture procedures according to the European standards were followed. Finally, several cylindrical specimens and slabs were compacted.

\section{Thermal Characterization of the Fibers}

In order to investigate the thermal transitions of these three types of fibers, a differential scanning calorimeter (DSC) from PerkinElmer (United States) was used. Samples of $5 \pm 1 \mathrm{mg}$ were prepared for the DSC analysis. The heating ramps were conducted at a rate of $20^{\circ} \mathrm{C} / \mathrm{min}$. Furthermore, the thermal stability of the fibers was analyzed by thermal gravimetric analysis (TGA) under a nitrogen atmosphere using TGA 209 from NETZSCH (Germany).

\section{Water Sensitivity}

Water sensitivity tests were performed according to the European standard EN 12697-12 (European Committee for Standardization European Standard [CEN], 2018). Hence, a set of eight Marshall specimens $(D=100 \mathrm{~mm}, h=60 \mathrm{~mm})$ was divided into two equally sized subsets and conditioned. One subset was maintained dry in a climate chamber at 
$22^{\circ} \mathrm{C}$ while the other subset was saturated and stored in water at elevated conditioning temperature $\left(40^{\circ} \mathrm{C}\right)$ for $72 \mathrm{~h}$. After conditioning, the indirect tensile strength of each of the two subsets was determined in accordance with EN 12697-23 (European Committee for Standardization European Standard [CEN], 2003b) at the specified test temperature of $22^{\circ} \mathrm{C}$ (Eq. 1). The ratio of the indirect tensile strength (ITS) of the water conditioned subset compared to that of the dry subset was determined in accordance with Eq. 2 and expressed in percentage (\%).

$$
\begin{gathered}
I T S=\frac{2 F}{\pi D h} \\
I T S R=100 \cdot \frac{I T S_{w}}{I T S_{d}}
\end{gathered}
$$

where ITS is the indirect tensile strength $(\mathrm{kPa}), F$ is the force $(\mathrm{N}), \mathrm{D}$ and h diameter and the height $(\mathrm{mm})$, respectively, ITSR the indirect tensile strength ratio $(\%) ; I T S_{\mathrm{W}}$ the average indirect tensile strength of the wet group in $(\mathrm{kPa}) ; I_{\mathrm{d}}$ the average indirect tensile strength of the dry group.

\section{Resistance to Fatigue}

The fatigue resistance was investigated based on the adapted German standard AL-Sp-Asphalt 09, which has been included in the European Standard EN 12697-24 (European Committee for Standardization [CEN], 2007). Cylindrical Marshall specimens were used to perform indirect tensile tests (IDT), while a continuous sinusoidal load was applied. The loading frequency of $10 \mathrm{~Hz}$ and a constant temperature of $20^{\circ} \mathrm{C}$ were used in this study. Through the vertical load, a state of stress is produced in the middle of the specimen that leads to its eventual failure. According to the standards, three loading amplitudes, $0.05 \%$ to $0.3 \%$, are implemented allowing the loading cycles to reach the fatigue criterion (Eq. 4). A total of nine specimens were tested, three at each of three strain levels.

According to the standard, two parameters were selected to evaluate the fatigue resistance: the numbers of loading cycles $\left(N_{\text {macro }}\right)$, when energy ratio $(E R)$ reaches its peak, as the product of the number of cycles $(N)$ and stiffness modulus $[E(N)]$ :

$$
E R(N)=|E(N)| N
$$

Additionally, the Wöhler line (Eq. 4) can be used to express the material's fatigue function. Hence, a minimum of three different strain amplitudes is required for each testing condition.

$$
N_{\text {Macro }}=C_{1} \cdot \varepsilon_{e l}^{C_{2}}
$$

where, $\varepsilon_{\mathrm{el}}$ is the horizontal elastic initial strain and C1, C2 are fitting constants.

Furthermore, from the fatigue line the classical parameter $\varepsilon_{6}$ defined as strain to reach one million cycles was also calculated.

\section{Rutting Resistance}

Rutting resistance (permanent deformation) tests were carried out by using the large device wheel tracking test according to the European Standard EN 12697-22 (European Committee for
Standardization European Standard [CEN], 2003a). In this test, the susceptibility of asphalt mixture to deform was controlled by the rut formed by repeated passes of a loaded wheel at a constant temperature of $60^{\circ} \mathrm{C}$. The wheel tracking tests are conducted on two laboratory compacted slabs per asphalt mixture $(500 \mathrm{~mm} \times 180 \mathrm{~mm} \times 100 \mathrm{~mm})$. After a zero measurement the relative rut depth, i.e., the absolute rut depth as a percentage of the specimen height, was determined at different time intervals. For mixture AC B $22 \mathrm{H}$ according to the Swiss standard (VSS, 2013), the rut depth after 30000 load passings (one passing includes one forth and back) is relevant.

\section{Imaging Analysis}

Samples of the FRAMs were evaluated using the Environmental Scanning Electron Microscope (ESEM). For this purpose, specimens $(28 \mathrm{~mm} \times 47 \mathrm{~mm} \times 10 \mathrm{~mm})$ were cut from the center of cylindrical specimens. The samples were impregnated with resin and polished using sand paper and water as lubricant. More details about the sample preparation can be found elsewhere (Cavalli et al., 2016). The ESEM experiments were performed with an FEI Quanta 650 by Thermo Fisher (United States). This study was conducted in the low vacuum mode in order to avoid any specimen perturbations. Specifically, lower inert gas purge (IGP) of $1.9 \times 10^{-7} \mathrm{mbar}$ and upper IGP equal to $1.2 \times 10^{-9}$ mbar and current emission of $309 \mathrm{~mA}$. Moreover, the ESEM analysis was performed with EDX (Energy Dispersive X-Ray Spectroscopy) option for chemical analysis.

\section{Bitumen Recovery and Rheological Analysis}

To understand the chemical effect, if any of the different types of fibers on the behavior of the experimental mixtures, samples of bitumen were extracted from the different asphalt mixtures with toluene. Then, the bitumens were recovered by rotatory evaporator according to the European Standard EN 12697-3 (European Committee for Standardization European Standard [CEN], 2018). The rheological responses and softening properties of these samples were evaluated. In this study, master curves obtained from rheological measurements conducted with a dynamic shear rheometer (DSR) Physica MCR 301 from Anton Paar (Austria) were analyzed. The parallel plate configuration with diameters of $8 \mathrm{~mm}$ and $25 \mathrm{~mm}$ corresponding to test sample thicknesses of $2 \mathrm{~mm}$ and $1 \mathrm{~mm}$, respectively, was used. A constant strain amplitude of $1 \%$ for high-temperature range $\left(40^{\circ} \mathrm{C}-80^{\circ} \mathrm{C}\right)$ and $0.1 \%$ for low temperature range $\left(40^{\circ} \mathrm{C}-0^{\circ} \mathrm{C}\right)$ with testing frequencies between 0.1 and $20 \mathrm{~Hz}$ at each temperature were used. Peltier Systems H-PTD200 and PPTD200 were used for controlling the sample temperature.

\section{DISCUSSION OF THE EXPERIMENTAL RESULTS}

In an asphalt plant, the blending conditions of the asphalt binder components depend on the type of asphalt mixing adopted. Hot mixing of asphalt at temperatures from $130^{\circ} \mathrm{C}$ to $160^{\circ} \mathrm{C}$, depending on the binder viscosity, is the common 
technology for preparing asphalt mixtures. The required mixing temperature should provide sufficiently low viscosity of asphalt binder to ensure full coating of all aggregates. Therefore, the fibers must be able to survive these temperatures and mechanically tough mixing conditions. In order to investigate such conditions, the fibers type A (aramid and polyolefins) and type $\mathrm{P}$ (polyacrylonitrile) were subjected to heating ramps using TGA. The measured weight loss of the fibers with the increase of temperature is shown in Figure 2.

It can be observed that for both fibers forming type A (aramid and poyolefins), the weight of the sample is kept practically constant until temperatures above $400^{\circ} \mathrm{C}$. This means that, at conventional temperatures for hot asphalt mixes $\left(\mathrm{ca} .160^{\circ} \mathrm{C}\right)$, the fibers will not suffer any thermal degradation. Regarding the fiber type $\mathrm{P}$ (polyacrylonitrile), the weight loss starts at a temperature of $280^{\circ} \mathrm{C}$. It can be also seen that the curve has different steps that indicate the degradation of components that decompose differently when exposed to temperature. Nevertheless, these temperatures are still far from the mixing temperatures normally used in standard asphalt mixing procedures, so, it can be confirmed that no thermal effect is expected for this kind of fiber either.

The fibers were also thermally analyzed for a large temperature range (from $20^{\circ} \mathrm{C}$ to $500^{\circ} \mathrm{C}$ ) by differential scanning calorimetry in order to study their thermal transitions. The heat flow curves for fibers type A and $\mathrm{P}$ are given in Figure 3.

During the mixing process at high temperatures, the fibers could melt and hypothetically react chemically with the bitumen and modify it. This could then change the binder properties affecting the performance of the asphalt mixtures. In Figure 3, it can be observed that aramid fibers (type A1) showed a melting temperature above $400^{\circ} \mathrm{C}$, so no chemical modification is expected to occur and any effect on the response of the FRAM will be due to a physical interaction. On the other hand, the polyolefin fibers (type A2) showed a melting temperature of $124.5^{\circ} \mathrm{C}$ which is lower than the mixing temperature used for the experimental FRAMs (i.e., $160^{\circ} \mathrm{C}$ ). It is important to notice that, although the concentration of this type of fibers was low (lower than $0.05 \%$ wt.),

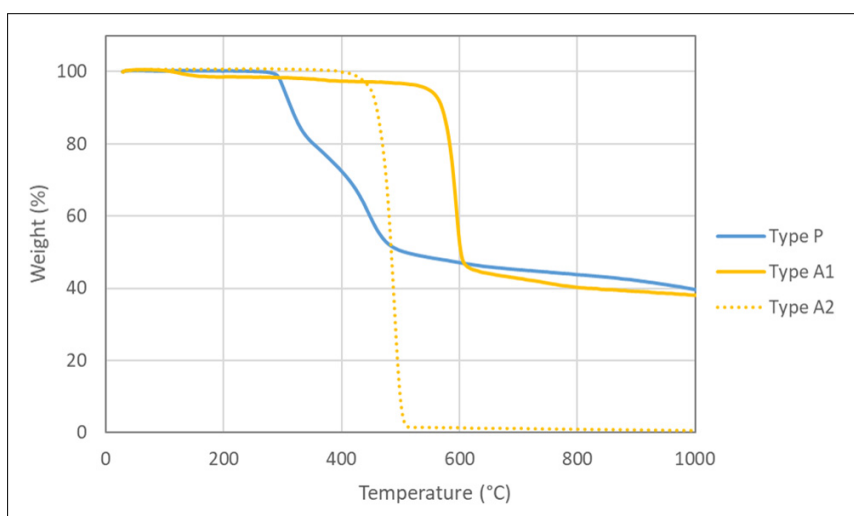

FIGURE 2 | Weight loss of fibers versus temperature during TGA heating ramps. Type $\mathrm{P}$ (polyacrylonitrile fiber) and type $\mathrm{A}$ (aramid and polyolefins fibers).
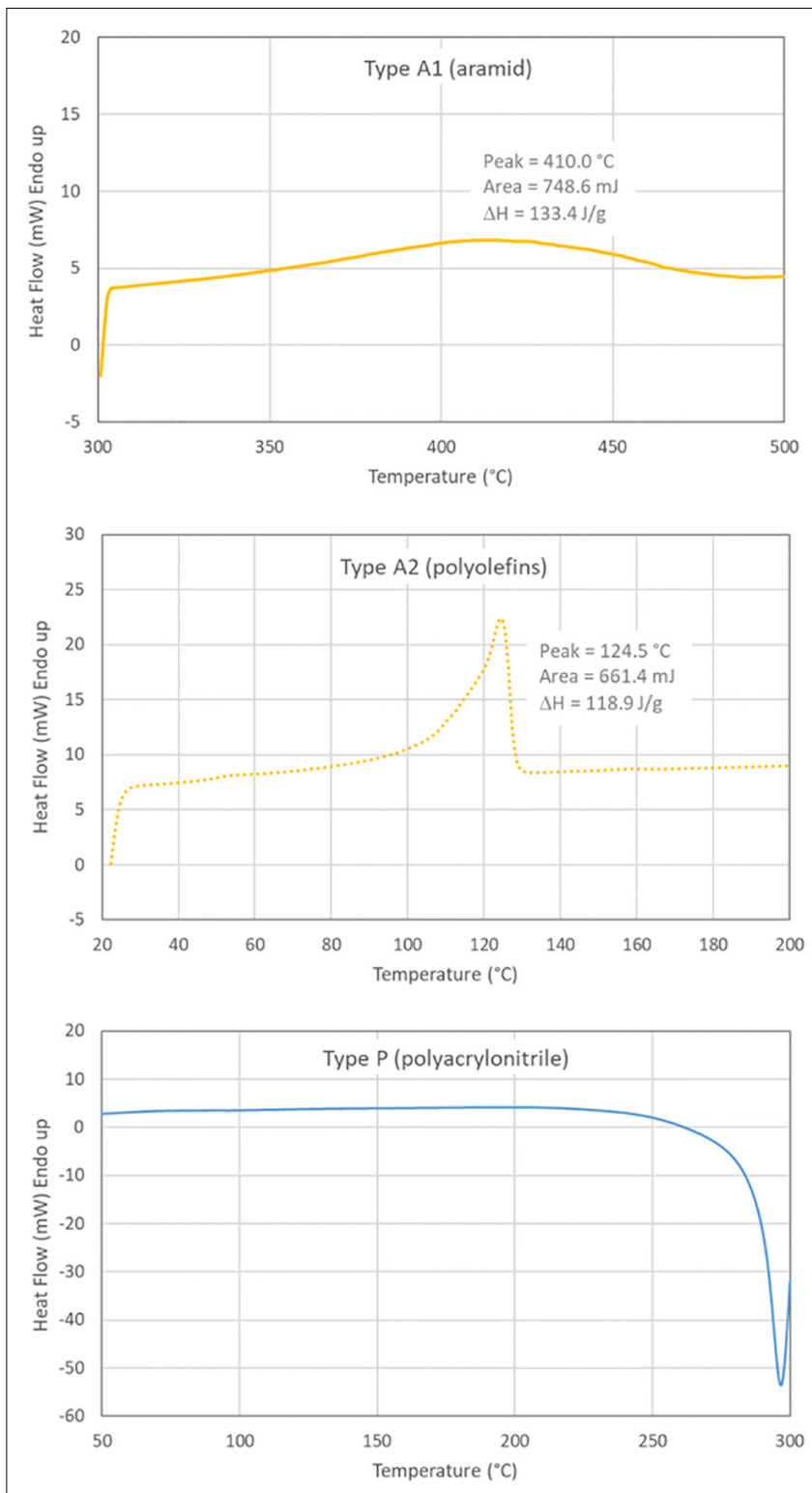

FIGURE 3 | Heat flow curves versus temperature for the different fibers studied. Aramid fiber (top), polyolefins fiber (medium) and polyacrylonitrile fiber (bottom).

the addition of the polyolefin fibers was recommended to be done directly into the hot binder. This fact could lead to a modification of the bitumen influencing the behavior of the corresponding FRAM (ACB22H-type A).

Concerning the polyacrylonitrile fibers (type P), the DSC measurement (Figure 3) shows a sharp exothermic peak close to $300^{\circ} \mathrm{C}$. This could mean the fiber already starting decomposing at this temperature. This behavior coincides with the result observed from TGA. In this sense, the fiber degrades before reaching its melting temperature $\left(\mathrm{ca} .350^{\circ} \mathrm{C}\right)$. As a consequence, energy freed from this initial degradation could locally raise the temperature. 


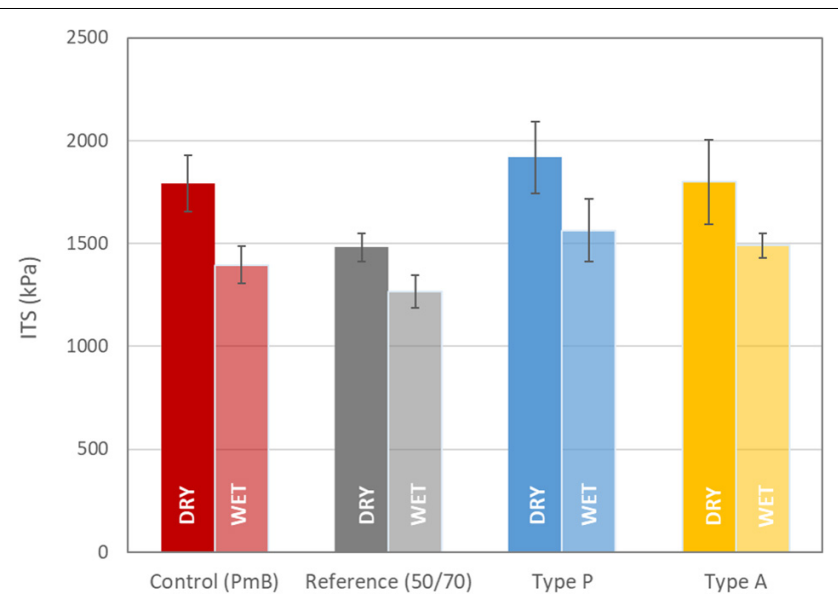

FIGURE 4 | Indirect Tensile Strength (ITS) results for the mixtures in dry and wet conditions.

Figure 4 shows the mechanical response of the different asphalt mixtures as comparison results between dry and wet conditions with the indirect tensile strength (ITS). It can be seen that the asphalt mixtures prepared with both fibers result in a higher ITS compared to the ones without fibers (control and reference) in both dry and wet conditions. The highest ITS value was found for the FRAM with Type P fiber (1918 kPa), then followed by the one with Type A fiber (1798 $\mathrm{kPa}$ ) with similar values to the control mixture prepared with PmB (1791 kPa). The reference mixture prepared with the unmodified bitumen $50 / 70$ obtained the lowest ITS value $(1482 \mathrm{kPa})$. The influence of the incorporation of fibers on the strength can be clearly observed which could be attributed to a reinforcing effect in the experimental FRAMs.

The water sensitivity can be interpreted using the indirect tensile strength ratio (ITSR). These results are shown in Figure 5. A different trend was found in ITSR compared to the previous observation. It can be seen that FRAMs obtained higher ratios (81.4\% for Type P fiber and $82.8 \%$ for Type A fiber) compared to the control mixture with $\mathrm{PmB}$ (77.9\%). In this case, regarding the ITSR, the reference mixture prepared with the unmodified bitumen 50/70 showed the best moisture resistance capability $(85.4 \%)$. To conclude, it was confirmed that FRAMs would fulfill the Swiss normative requirements of ITSR by reaching rates higher than $70 \%$, which indicates reliable moisture distress resistance. Referring to Figure 4, it is clear that ITSR is only an indication of the ratio of wet to dry strength and not the strength itself. To this end, it is noteworthy to indicate that the reference mixture had the lowest strength but higher ITSR.

Figure 6 displays all the testing results based on the fatigue experimental measurements. In the graph on the top, to determine the Wöhler lines, the number of loading cycles to fatigue failure $\left(N_{\text {macro }}\right)$ were recorded and then plotted in a loglog plane against the initial strain level $\left(\varepsilon_{\mathrm{el}}\right)$. Moreover, the initial stiffness (98-102 cycles) obtained for the four different materials is shown and compared as a bar chart (bottom graph). The results of fatigue tests indicate that good repeatability was achieved

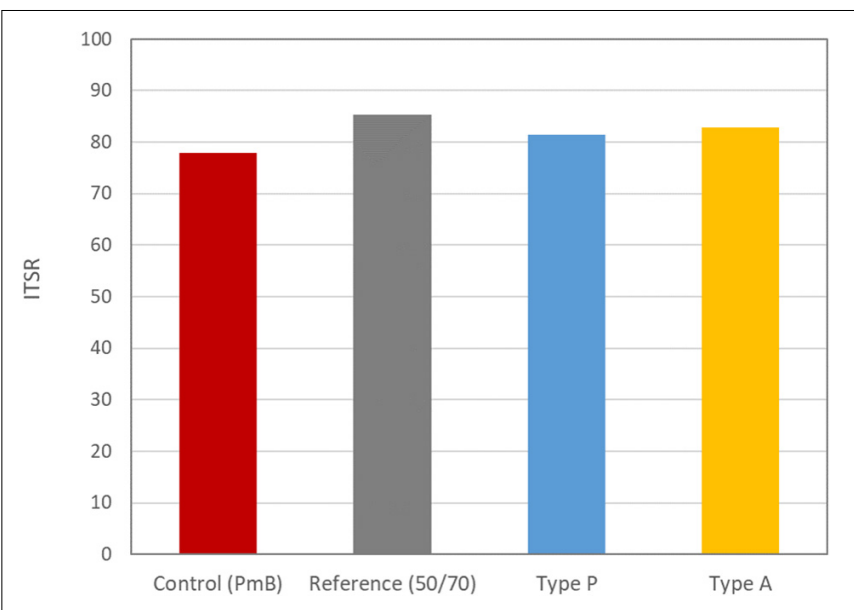

FIGURE 5 | Water sensitivity testing results by using ITSR (\%).

at each strain level for all materials tested. The fatigue lines calculated with an exponential fit and the correlation coefficient $\mathrm{R}^{2}$ are shown in the Figure 6. All $\mathrm{R}^{2}$ values are higher than 0.9 indicating a good correlation which satisfies the requirement by the standard which is 0.8 for base courses. The overall results indicate that the addition of fibers in the FRAMs could improve the fatigue response for lower strains whereas similar results to the reference mixture were obtained for higher strain levels. A similar conclusion was obtained in a previous work for asphalt mixtures reinforced with aramid fibers (Klinsky et al., 2018). These experimental mixtures were only recommended for roads with moderate to low deflection levels. Likewise, some authors claimed that the improvement of fatigue life found in asphalt mixtures with polyacrylonitrile fibers could be attributed to different phenomena such as the fiber's absorption and adhesion of bitumen or the reallocation of stresses (Xu et al., 2010). In our case, concerning fatigue resistance performance, none of FRAMs reached the performance observed for the reference mixture $(\mathrm{PmB})$. This fact could be related to the higher stiffness values observed for the FRAMs in comparison to the values for reference mixture. In addition, the polymer modification provides a different three-dimensional reinforcement that the fibers cannot duplicate.

In Figure 7, the resistance to permanent deformations as rutting depth (\%) results is illustrated for all the four mixtures. FRAM modified with fiber type $\mathrm{P}$ showed a similar performance in comparison to the control mixture $(\mathrm{PmB})$. Nevertheless, the FRAM with type A fiber obtained a worse response against permanent deformation, while the hardness of the unmodified bitumen led to a remarkable rutting resistance of the reference mixture. Again, the significant influence of the fibers addition on the response of the mixtures can be observed. It can be noticed that the FRAM modified with Type A fibers (8.2\%) would not fulfill Swiss requirements for this type of mixtures which require values lower than $7.5 \%$ after 30000 cycles. These results contradict the performance reported in previous studies where the addition of fibers led to lower deformations at high 

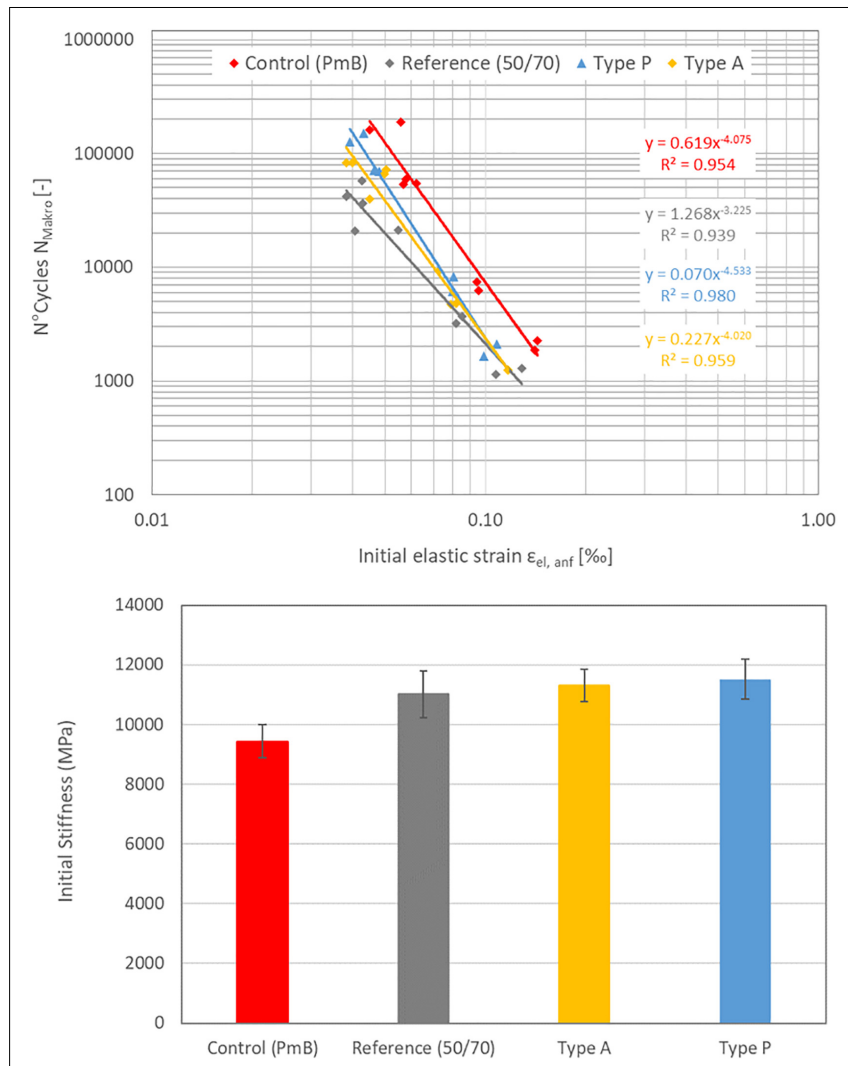

FIGURE 6 | Fatigue testing results for three different loading amplitudes at $f=10 \mathrm{~Hz}$ and at a test temperature of $20^{\circ} \mathrm{C}$ : loading cycles to fatigue failure Nmacro vs. initial strain level $\varepsilon_{\text {el }}$ (top); initial stiffness (bottom).

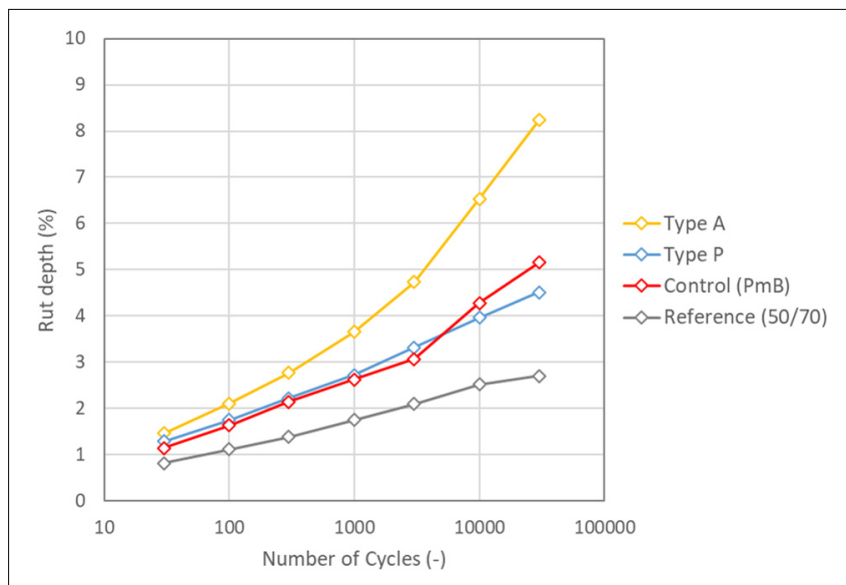

FIGURE 7 | Rutting (wheel tracking) testing results for different mixtures.

temperature in comparison with unmodified mixtures (Xu et al., 2010; Mirabdolazimi and Shafabakhsh, 2017; Klinsky et al., 2018).

In parallel to the mechanical characterization, imaging analyses were carried out for different samples to visualize the fibers within the asphalt matrix in order to understand their role based on this aspect. The use of the EDX technique helped to identify the fibers thanks to the analysis of the
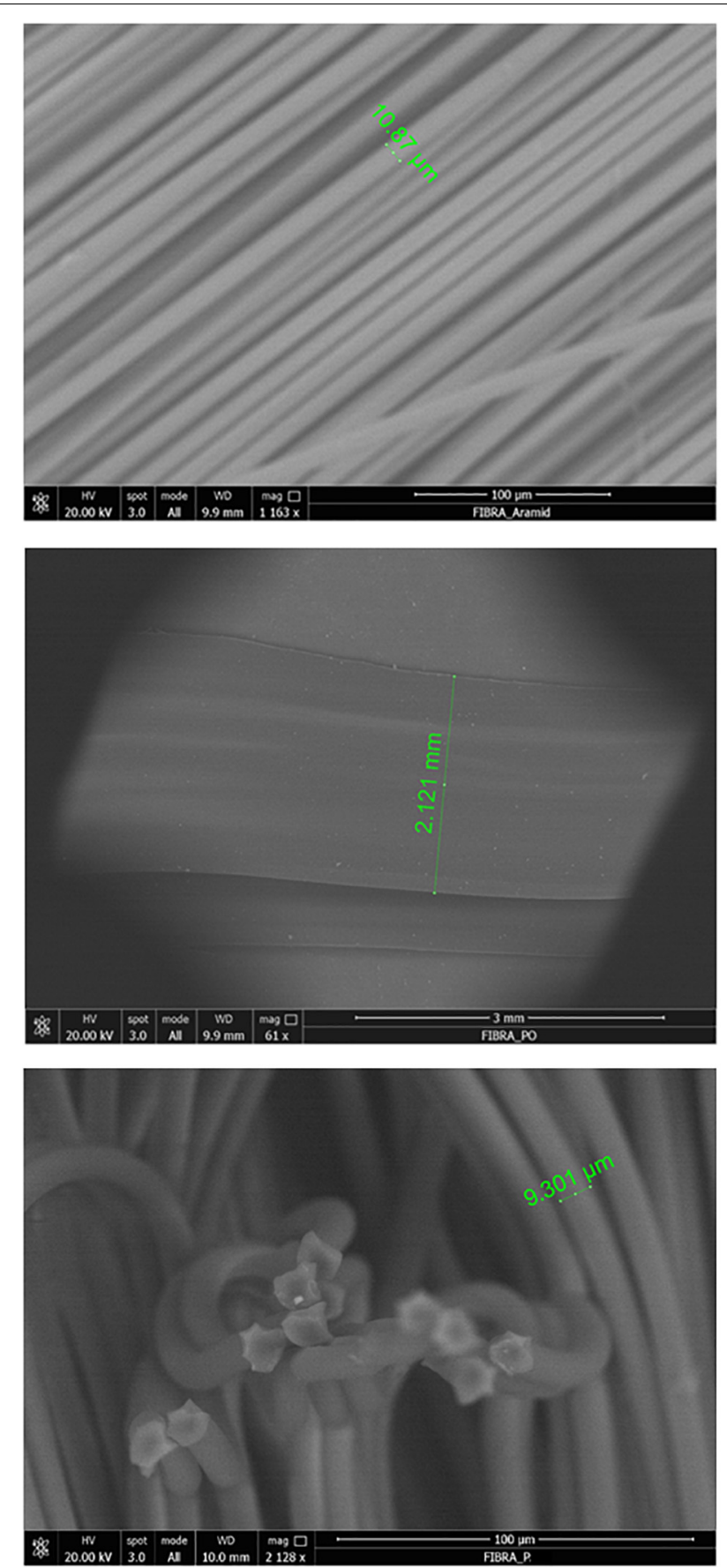

FIGURE 8 | ESEM micrographs of aramid fibers (type A1), polyolefin fiber (type A2), and polyacrylonitrile fibers (type P).

chemical elements. First, single analyses of the fibers were done to characterize their chemical compositions. ESEM images of polyolefin, aramid and polyacrylonitrile fibers and their elemental analyses of characteristic points are shown in Figure 8 and Table 2, respectively.

The EDX analysis of the polyolefin fibers (type A2) indicates that they contain mainly carbon elements. This means that, 
TABLE 2 | Elemental analysis (atom\%) of the fibers.

\begin{tabular}{lcccccc}
\hline & C & N & O & Na & S & Si \\
\hline Aramid (Type A1) & 61.24 & 21.08 & 17.28 & 0.29 & 0.11 & - \\
Polyolefin (Type A2) & 100.00 & - & - & - & - & - \\
Polyacrylonitrile (Type P) & 52.30 & 38.73 & 8.78 & - & - & 0.19 \\
\hline
\end{tabular}

if these fibers were not melted during the mixing process, as discussed in the previous section, this fact will make it more difficult to identify them within the asphalt matrix which also contains hydrocarbons. Concerning the elemental analysis of the aramid fibers (type A1), it can be seen that more atoms appear (N, O or S) which reveals the presence of their characteristic amide groups. These particularities will later help to analyze the micro-images from the FRAM modified with fibers type A. Likewise, the EDX analysis of the fibers type P (polyacrylonitrile) indicates that they primarily consist of carbon (C), nitrogen (N) and oxygen $(\mathrm{O})$. This is directly related to the presence of the acrylonitrile groups. In this case, the presence of nitrogen will be crucial to identify these fibers mixed with the asphalt and mineral aggregates.

Next, the ESEM images from the sample of the FRAMs using fibers type A (aramid + polyolefins) and type $\mathrm{P}$ (polyacrylonitrile) are shown in Figure 9. The presence of some aramid fibers (identified by their unusual shape and chemical analysis) can be clearly seen. Polyolefin fibers could have been melted during the mixing process due to their thermal properties and therefore it cannot be expected that these fibers would be visible in the images.

Similarly, the presence of parts of fibers type P can be clearly observed in Figure 9 (right). These are more homogeneously distributed consequence of their higher concentration $(0.15 \%)$ compared to the FRAM modified with fibers type A $(0.05 \%)$.

Finally, samples from the different mixtures were extracted and the bitumen recovered in order to study whether the fibers had any chemical effect on the binders. A potential bitumen
TABLE 3 | Bitumen properties before and after mixing and extraction processes.

\begin{tabular}{lccc}
\hline & & & Softening point \\
\hline Original & Reference & $50 / 70$ & $49.0^{\circ} \mathrm{C}$ \\
& Control & $\mathrm{PmB}$ & $66.4^{\circ} \mathrm{C}$ \\
After recovery & Reference & $50 / 70$ & $55.0^{\circ} \mathrm{C}$ \\
& Control & $\mathrm{PmB}$ & $66.8^{\circ} \mathrm{C}$ \\
& ACB22H $-\mathrm{P}$ & $50 / 70+$ type P & $55.5^{\circ} \mathrm{C}$ \\
& ACB22 $\mathrm{H}-\mathrm{A}$ & $50 / 70+$ type A & $56.1^{\circ} \mathrm{C}$ \\
\hline
\end{tabular}

modification was mainly expected as a consequence of the melted polyolefins fibers. The samples of the different bitumens recovered from the experimental mixtures were first tested to evaluate their softening point. These results, along with the properties of both bitumens in their original state, are shown in Table 3.

First, it can be seen that there is an aging effect on the unmodified bitumen 50/70 which leads to an increase of the softening point from $49^{\circ} \mathrm{C}$ to $55^{\circ} \mathrm{C}$. This effect was not observed in the polymer modified bitumen used for the control mixture. Regarding the influence of the fibers, at mixing temperature $\left(160^{\circ} \mathrm{C}\right)$, a chemical modification of the bitumen could be expected by the polyolefin fibers (type A2) due to their melting temperature $\left(124^{\circ} \mathrm{C}\right)$. Nevertheless, it can be confirmed that there was no chemical modification due to any of the fibers. Values obtained for the bitumens recovered from the FRAMs are quite similar to that obtained for the reference mixture. Therefore, the increase of the softening point must be attributed to the aging effect during the mixing process.

This behavior could be observed in more detail in Figure 10 where the rheological analysis is shown. In these graphs, the master curves as well as the black curves obtained from the different bitumen samples indicate that the recovered polymer modified bitumen is the only one showing a different response. On the other hand, the binders from the FRAMs present a similar response to the one from the reference mixture (unmodified
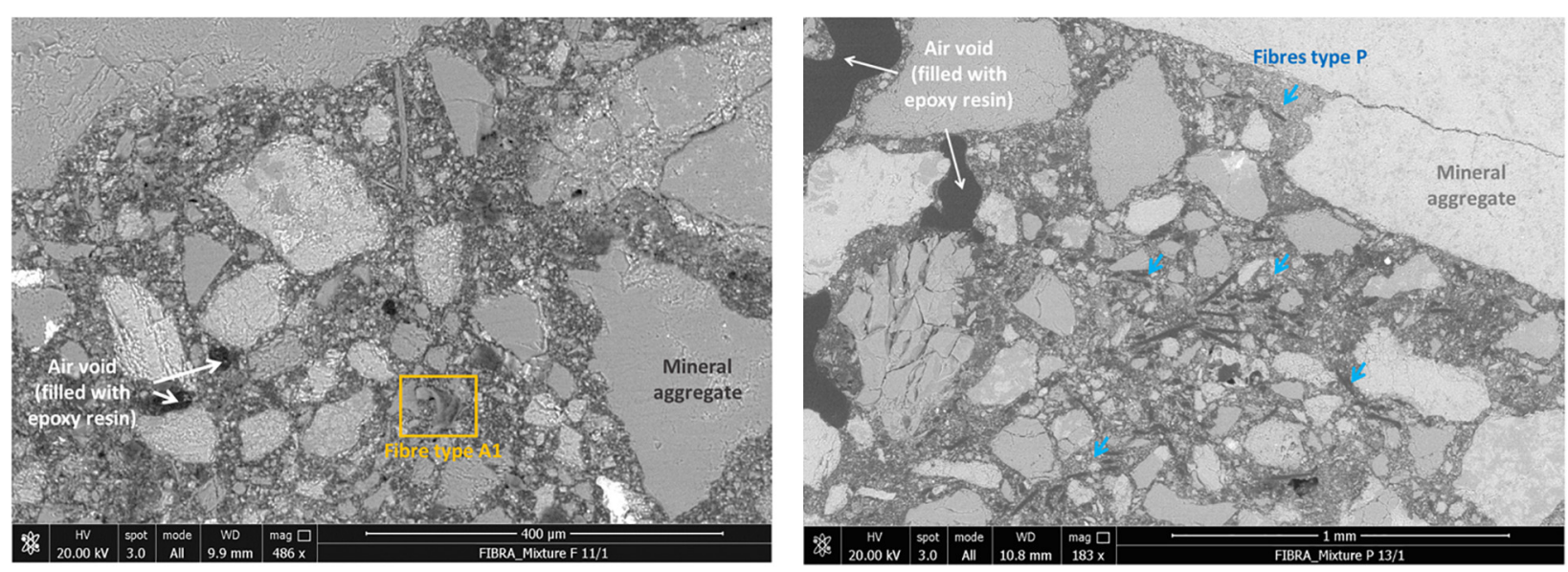

FIGURE 9 | ESEM images of samples from the FRAM with type A fibers (left) and type $P$ fibers (right). The arrows try to help the analysis by pointing at the fibers (Type P). 

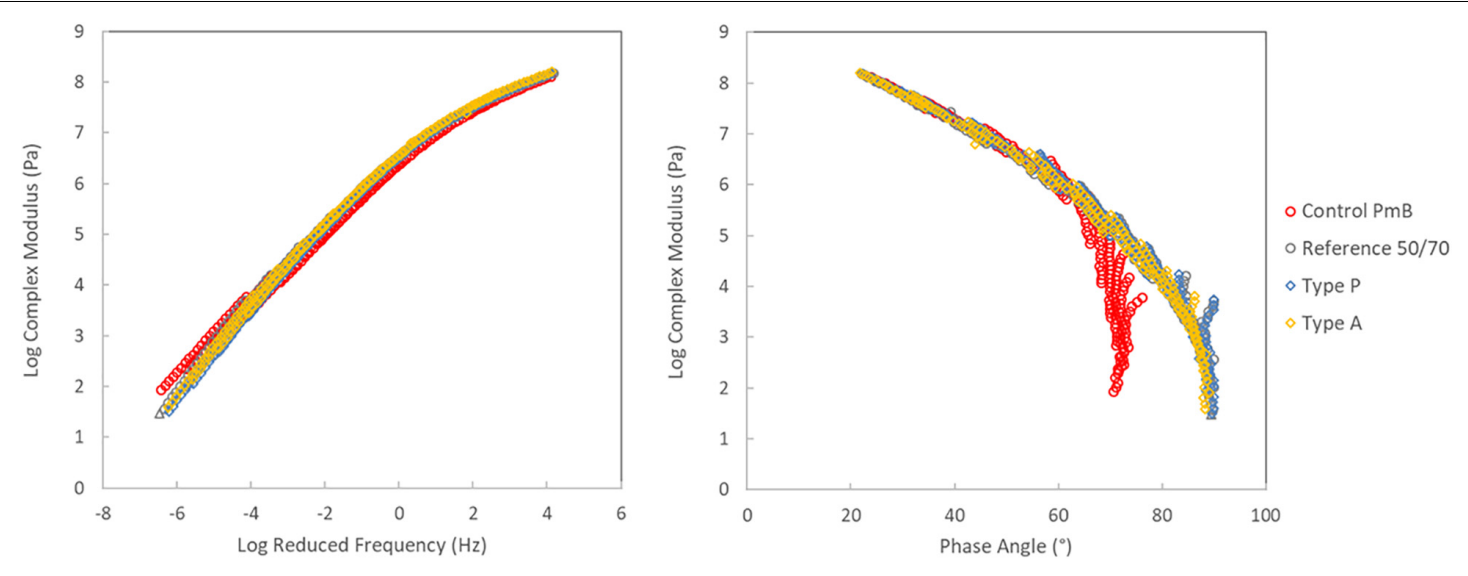

FIGURE 10 | Master curves (left) and Black curves (right) of the different bitumen samples after extraction.

bitumen 50/70) confirming that the addition of fibers did not alter the binder.

\section{SUMMARY AND CONCLUSION}

In this work, the suitability of certain fibers for fiber reinforce asphalt mixtures (FRAMs) is experimentally investigated. Two commercially available fibers were used for this purpose, i.e., type A (a blend of aramid and polyolefins fibers) and type $\mathrm{P}$ (polyacrylonitrile fibers). Four different AC B $22 \mathrm{H}$ mixtures with and without fibers were prepared for comparison purposes. Water sensitivity, rutting resistance and fatigue resistance tests were performed. Furthermore, the thermal characterization of the selected fibers, image analysis of samples of the FRAMs and the evaluation of the bitumen recovered were carried out. These studies aimed at understanding the chemo-mechanical mechanisms behind the performance obtained for the FRAMs.

Based on the testing results, the following conclusions can be drawn:

- Similar water sensitivity properties were found between the FRAMs prepared with fibers and the reference one prepared with polymer modified bitumen $(\mathrm{PmB})$. The positive effect of the addition of the fibers was observed when comparing it with the reference mixture prepared with the same unmodified bitumen (50/70) used as a base bitumen. In this sense, it was confirmed that FRAMs would fulfill the Swiss normative water sensitivity requirements of ITSR for this type of mixtures by reaching rates higher than $70 \%$.

- After analyzing the performance obtained for the rutting resistance test, it can be concluded that the FRAM modified with Type $\mathrm{P}$ fibers behaves similarly to the control mixture $(\mathrm{PmB})$. Whereas, the FRAM with type A fibers showed deeper ruts at $60^{\circ} \mathrm{C}$. Therefore, only FRAM with fiber type $P$ satisfied the current Swiss requirements.

- The incorporation of both types of fibers improved the fatigue response of the mixture with respect to the unmodified bitumen (reference) at lower strain levels.
Nevertheless, this modification would not reach the general performance against fatigue distresses observed for the control mixture prepared with PmB.

- The imaging analysis with ESEM plus EDX method has confirmed the presence of polyacrylonitrile (type P) fibers and aramid fibers (type A1) within the asphalt matrix after going through the mixing and compaction process. This confirms the improvement of the mechanical properties of the FRAMs is directly related to a physical influence of the fibers.

- The thermal analysis of the fibers indicate that no degradation will happen during the mixing process due to the temperature. Besides, since their melting temperatures were found to be higher than the mixing temperatures, polyacrylonitrile (type $\mathrm{P}$ ) fibers and aramid fibers (type A1) will remain in solid state. However, the melting temperature for the polyolefin fibers (type A2) was found to be lower, thus, they could melt and modify the bitumen. This effect could be amplified for the addition of these type of fibers directly to the hot bitumen.

- Nevertheless, after extraction and recovery of the bitumens from the different asphalt mixtures, no significant modification due to the addition of the fibers was observed. The possible melting of the polyolefin fibers (type A2) does not affect the bitumen properties. The chemical composition of these fibers (mainly carbon) made it impossible to distinguish them within the asphalt matrix in the ESEM analysis. Therefore, it is not clear if these fibers survive the mixing process (small mixing times) and play a reinforcement role like the other fibers evaluated in this study.

Although the results obtained in this study are promising, additional experimental support is needed by extending the present research effort to the investigation of more types of asphalt bitumen and fiber types as well as construction of test sections to determine their in situ performance. Ultimately, the cost of such fibers will determine if they can compete with polymer modified binders. 


\section{DATA AVAILABILITY STATEMENT}

The datasets generated for this study are available on request to the corresponding author.

\section{AUTHOR CONTRIBUTIONS}

MB and LP designed the experiment plan, supervised the findings, and discussed the results. $\mathrm{MB}$ wrote the main manuscript. LP reviewed the manuscript.

\section{REFERENCES}

Aliha, M. R. M., Razmi, A., and Mansourian, A. (2017). The influence of natural and synthetic fibers on low temperature mixed mode I + II fracture behavior of warm mix asphalt (WMA) materials. Eng. Fract. Mech. 182, 322-336. doi: 10.1016/j.engfracmech.2017.06.003

Button, J. W., and Hunter, T. G. (1984). Synthetic Fibers in Asphalt Paving Mixtures. Texas: Texas A\&M University System College Station.

Cavalli, M. C., Griffa, M., Bressi, S., Partl, M. N., Tebaldi, G., and Poulikakos, L. D. (2016). Multiscale imaging and characterization of the effect of mixing temperature on asphalt concrete containing recycled components. J. Microsc. 264, 22-33. doi: 10.1111/jmi.12412

Chen, H., and $\mathrm{Xu}, \mathrm{Q}$. (2010). Experimental study of fibers in stabilizing and reinforcing asphalt binder. Fuel 89, 1616-1622. doi: 10.1016/j.fuel.2009.08.020

European Asphalt Pavement Association [EAPA], (2017). Asphalt in figures 2017, Technical report. Brussels: EAPA.

European Committee for Standardization European Standard [CEN], (2003a). European Standard EN 12697-22 Bituminous Mixtures - Test Methods for Hot Mix Asphalt - Part 22: Wheel Tracking. Brussels: European Committee for Standardization European Standard.

European Committee for Standardization European Standard [CEN], (2003b). European Standard EN 12697-23 Bituminous Mixtures - Test Methods for Hot Mix Asphalt - Part 23: Determination of the Indirect Tensile Strength of Bituminous Specimens. Brussels: European Committee for Standardization European Standard.

European Committee for Standardization European Standard [CEN], (2018). EN 12697-12 Bituminous Mixtures - Test Methods - Part 12: Determination of the Water Sensitivity of Bituminous Specimens. Brussels: European Committee for Standardization European Standard.

European Committee for Standardization [CEN], (2007). European Standard EN 12697-24, Bituminous Mixtures - Test Methods for Hot Mix Asphalt - Part 24: Resistance to Fatigue. Brussels: European Committee for Standardization European Standard.

European Committee for Standardization [CEN], (2018). European Standard EN 12697-2, Bituminous Mixtures - Test Methods - Part 3: Bitumen Recovery: Rotary Evaporator. Brussels: European Committee for Standardization European Standard.

Ho, C. H., Shan, J., Wang, F., Chen, Y., and Almonnieay, A. (2016). Performance of fiber-reinforced polymer-modified asphalt two-year review in Northern Arizona. Trans. Res. Rec. 2575, 138-149. doi: 10.3141/2575-15

Kaloush, K. E., Biligiri, K. P., Zeiada, W. A., Rodezno, C., and Reed, R. X. (2010). Evaluation of fiber-reinforced asphalt mixtures using advanced material characterization tests. J. Test. Eval. 38, 400-411. doi: 10.1520/JTE10 2442

\section{FUNDING}

This research work project was funded by CEDR Transnational Road Research Program - call 2017 through the contract N. 867481, "Fostering the implementation of fiber-reinforced asphalt mixtures by ensuring its safe, optimized and cost-efficient use (FIBRA)". Scientific support from our Consortium Partners University of Cantabria (Spain), Technical University of Braunschweig (Germany), BAM (Netherlands), SINTEF and Veidekke (Norway) is gratefully acknowledged.

Klinsky, L. M. G., Kaloush, K. E., Faria, V. C., and Bardini, V. S. S. (2018) Performance characteristics of fiber modified hot mix asphalt. Const. Build. Mater. 176, 747-752. doi: 10.1016/j.conbuildmat.2018.04.221

Laurance, W. F., Clements, G. R., Sloan, S., O’Connell, C. S., Mueller, N. D., Goosem, M., et al. (2014). A global strategy for road building. Nature 513, 229-232.

Mirabdolazimi, S. M., and Shafabakhsh, G. (2017). Rutting depth prediction of hot mix asphalts modified with forta fiber using artificial neural networks and genetic programming technique. Const. Build. Mater. 148, 666-674. doi: 10.1016/j.conbuildmat.2017.05.088

Noorvand, H., Salim, R., Medina, J., Stempihar, J., and Underwood, B. S. (2018). Effect of synthetic fiber state on mechanical performance of fiber reinforced asphalt concrete, transportation research record. J. Transp. Res. Board 2672, 52-51. doi: 10.1177/0361198118787975

Simpson, A. L., and Mahboub, K. C. (1994). "Case study of modified bituminous mixtures: somerset, kentucky," in Proceedings of the 3 rd Materials Engineering Conference, (San Diego, CA: ASCE).

Slebi-Acevedo, C. J., Lastra-González, P., Pascual-Muñoz, P., and Castro-Fresno, D. (2019). Mechanical performance of fibers in hot mix asphalt: a review. Const. Build. Mater. 200, 756-769. doi: 10.1016/j.conbuildmat.2018.12.171

Souliman, M. I., Tripathi, A., and Isied, M. (2019). Mechanistic analysis and economic benefits of fiber-reinforced asphalt mixtures. J. Mater. Civil Eng. 31:04019142. doi: 10.1061/(ASCE)MT.1943-5533.0002755

VSS, (2013). Forschung und Normierung im Strassen- und Verkehrswesen 2013 Schweizer Norm 640 431-1c-NA. Asphaltmischgut Mischgutanforderungen Teil 1: Asphaltbeton. Zürich: Schweizerischer Verband der Strassen- und Verkehrsfachleute.

Weise, C., and Zeissler, A. (2016). "Effects of fiber reinforcement on the fatigue and rutting performance of asphalt mixes," in Proceedings of the 6th Eurasphalt \& Eurobitume Congress, Prague Czech Republic, Prague.

Xu, Q., Chen, H., and Prozzi, J. A. (2010). Performance of fiber reinforced asphalt concrete under environmental temperature and water effects. Const. Build. Mater. 24, 2003-2010. doi: 10.1016/j.conbuildmat.2010.03.012

Conflict of Interest: The authors declare that the research was conducted in the absence of any commercial or financial relationships that could be construed as a potential conflict of interest.

Copyright (C) 2020 Bueno and Poulikakos. This is an open-access article distributed under the terms of the Creative Commons Attribution License (CC BY). The use, distribution or reproduction in other forums is permitted, provided the original author(s) and the copyright owner(s) are credited and that the original publication in this journal is cited, in accordance with accepted academic practice. No use, distribution or reproduction is permitted which does not comply with these terms. 